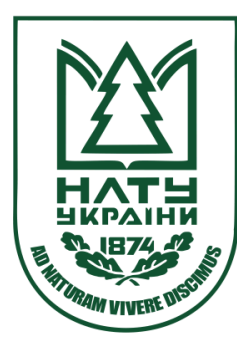

Науковий вісник НЛТУ України Scientific Bulletin of UNFU

https://nv.nltu.edu.ua

https://doi.org/10.15421/40280814

Article received 08.10.2018 p.

Article accepted 25.10.2018 p.

удк 712.41:635.921

ISSN 1994-7836 (print)

ISSN 2519-2477 (online)

$@ \bowtie$ Correspondence author

K. V. Myronchuk

k.myronchuk@chnu.edu.ua

К. В. Мирончук

Чернівецький національний університет ім. Юрія Федьковича, м. Чернівиі, Україна

\title{
КЛАСИФІКАЦІЯ МОБІЛЬНИХ ЖИВОПЛОТІВ
}

Для тимчасового або довгострокового озеленення урбанізованих територій, на яких немає можливості створення традиційних елементів озеленення, доцільно створювати мобільні живоплоти із застосуванням новітніх технологій. Моделювання процесів планування, створення і формування мобільних живоплотів має базуватися на поєднанні декоративного, агротехнічного та екологічного принципів, що надалі забезпечуватиме еколого-біологічну стабільність живих огорож та їх стійкість до впливу несприятливих природних і антропогенних чинників урбанізованого середовища. Вперше висвітлено класифікацію мобільних живоплотів, яка поділяе їх на дві групи - прості та каркасні мобільні живоплоти; за видовим складом - чисті та змішані; за висотою - низькі, середні та високі. Також за тривалістю використання на одному об'єкті озеленення виділено тимчасові, сезонні, довгострокові мобільні живоплоти. Залежно від розмірів, ваги однієї секції, що безпосередньо впливає на мобільність цього елементу озеленення, за можливістю переміщення поділяють на: високомобільні, середньомобільні та маломобільні. Наведено рекомендації щодо видового складу, використання мобільних живоплотів. Доведено, що мобільні живоплоти $є$ перспективними для використання їх у ландшафтному дизайні та озелененні територій.

Ключові слова: класифікація; мобільний живопліт; секції; каркас для мобільного живоплоту.

Вступ. Живі огорожі, як елемент садово-паркового мистецтва, набули різних форм і призначення, що дає змогу використовувати цей елемент озеленення у різних ландшафтних рішеннях. Сьогодні дедалі частіше в міському та заміському середовищі з'являються нові форми живих огорож. Серед яскравих представників нового покоління озеленення та ландшафтного дизайну треба виділити мобільні живоплоти (рис. 1).

Мета дослідження полягає в описі та моделювання, планування, розроблення процесів створення, формування мобільних живоплотів.

Викладення основного матеріалу дослідження. Мобільний живопліт - це живопліт, висаджений у контейнери (горщики, місткості), окремі секції якого за послідовного розташування утворюють розмежувальний елемент озеленення, котрий виконує функції традиційного живоплоту, на визначений відрізок часу.

Значна перевага мобільних живоплотів полягає в тому, що їх можна розміщувати на об'єктах, де немає потреби або неможливе створення традиційних елементів озеленення, на визначений відрізок часу. Це місця відпочинку, ресторани, кафе, літні майданчики, виставки, ярмарки, будівельні майданчики, місця реконструкцій будівель, пам'яток архітектури, під час заходів просто неба, розмежування пішохідних вулиць. Завдяки мобільним живоплотам можна обмежувати рух транспорту на певних відрізках дороги. Вони нададуть можливість швидко розмежувати простір і прикрасити теритоpiю (Blanc, 2018; Dahlgaard, 2014; Vont mettre, 2018; Simonova, 2018).

Під час будівельних, дорожніх, комунальних робіт на щільно заселених територіях мобільні живі огорожі можуть використовуватись як досить дієвий бар'єр, який забезпечить шумопоглинання, пиловловлювання та візуальне відокремлення (Myronchuk, 2016).
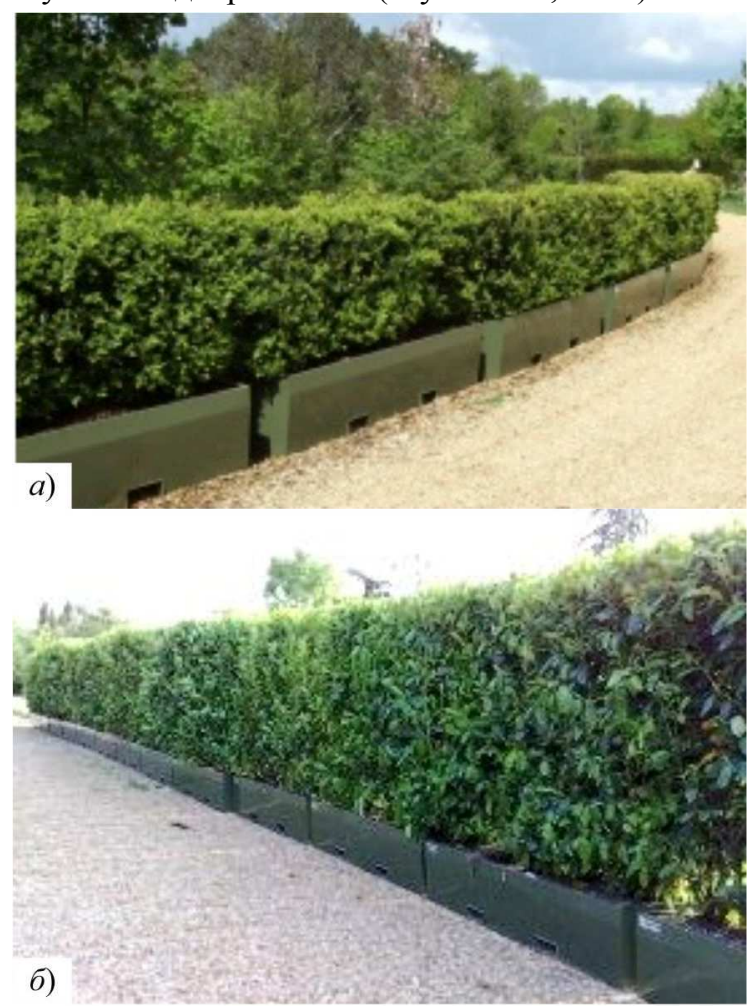

Рис. 1. Мобільні живоплоти

Мобільними живоплотами вважаємо різноманітні насадження кущових, деревних, витких рослин, що висаджують у прямокутні горшки, 3 подальшим форму-

Інформація про авторів:

Мирончук Катерина Василівна, канд. с.-г. наук, асистент. Email: k.myronchuk@chnu.edu.ua; https://orcid.org/0000-0001-5462-6226 Цитування за ДСту: Мирончук К. В. Класифікація мобільних живоплотів. Науковий вісник НЛтУ України. 2018, т. 28, № 8. С. 70-73. Citation APA: Myronchuk, K. V. (2018). Classification of mobile hedges. Scientific Bulletin of UNFU, 28(8), 70-73.

https://doi.org/10.15421/40280814 
ванням або встановленням у цю місткість металевих, дерев'яних каркасів. Найчастіше каркаси використовуються для підтримки в'юнких рослин, що сприяє наданню певної форми живій огорожі (Dahlgaard, 2014; Timur \& Karaca, 2013).

Мобільний живопліт рекомендують створювати невеликих розмірів - заввишки до 2 м і завширшки до 0,5 м, що забезпечить незначну вагу секції живої огорожі та дасть змогу за потреби швидко перемістити цей об'єкт на іншу місцевість. Для кращого розуміння доцільності та експлуатації мобільних живих огорож уперше розроблено класифікацію для правильного вибору мобільної одиниці (рис. 2).

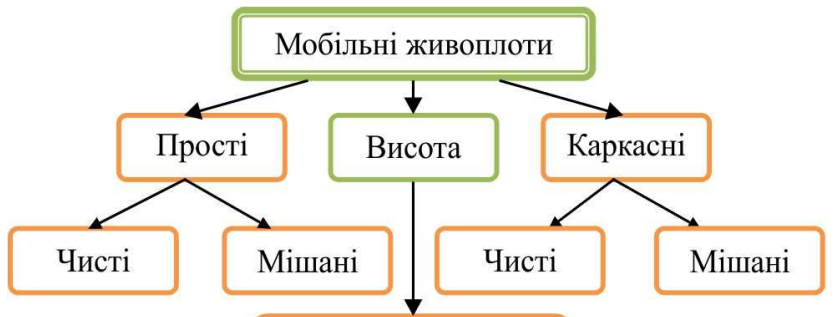

a)

Низькі - до 0,5м
Середні - 0,5-1м
Високі - більше 1м

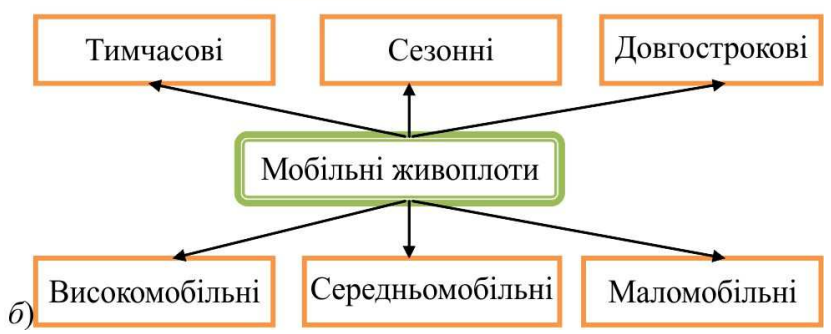

Рис. 2. Класифікація мобільних живоплотів

Мобільний живопліт поділяють на дві групи - прості та каркасні мобільні живоплоти (рис. 3), які класифікуються: за видовим складом - чисті та мішані; за висотою - низькі, середні та високі. Також класифікуються за тривалістю використання на одному об'єкті озеленення: тимчасові, сезонні, довгострокові. Залежно від розмірів, ваги однієї секції, що безпосередньо впливає на мобільність цього елементу озеленення, поділяють на: високомобільні, середньомобільні та маломобільні.
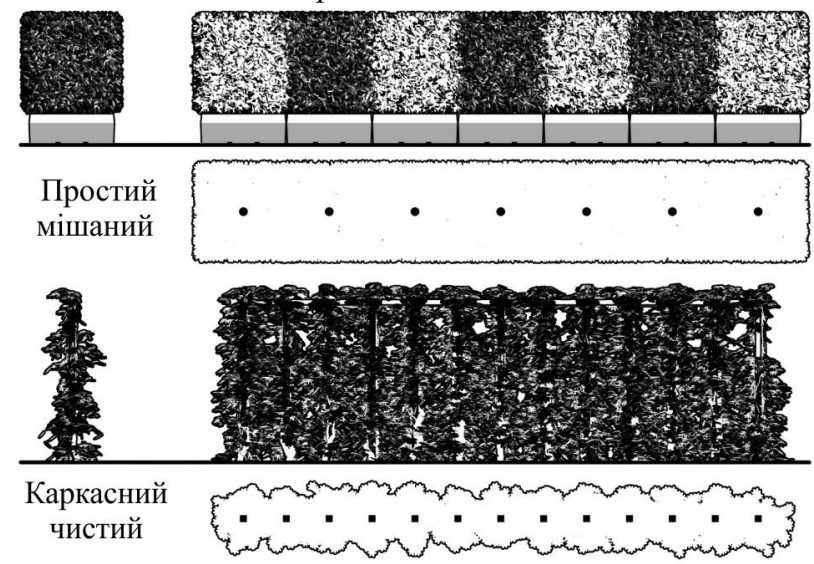

Рис. 3. Схема простого та каркасного мобільного живоплоту

Для створення простих мобільних живих огорож рекомендують використовувати такі вічнозелені рослини: Buxus sempervirens (L.); Thuja occidentalis 'Tiny Tim', 'Brabant', 'Danica', 'Teddy', 'Woodwardii'; Thuja plicata 'Can - Can'; Berberis thunbergii, B. Vulgaris (L.), B. Amu- rensis (Rupr.), та їх різні низькорослі сорти, також пропонуємо Prunus laurocerasus (L.); Taxus cuspidata 'Nana' (Siebold \& Zucc.), T. Baccata 'Groenland' (L.); Pinus nigra 'Globosa' (J. F. Arnold.), P. sylverstris 'Aurea' та 'Watereri' (L.), тощо. Для створення каркасних мобільних живих огорож використовують опору для рослин - каркас, який надає різноманітну форму та прикрашає структурну композицію.

Каркаси виготовляють з металу, пластику та дерева. Металеві каркаси характеризуються довговічністю та високою естетичністю, яку надають ковані елементи. Різноманітні прикраси, які проглядаються на фоні живої огорожі, часто застосовують по периметру всієї площини живої огорожі. Дерев'яні каркаси мають менший час експлуатації порівняно $з$ металевими та пластиковими. Пластикові каркаси найдешевші, не потребують додаткового оброблення порівняно 3 дерев'яними, але не мають достатньо високого естетичного вигляду. Також зазначимо, що пластикові каркаси потрібно використовувати як серцевину у структурі живої огорожі (рис. 4).

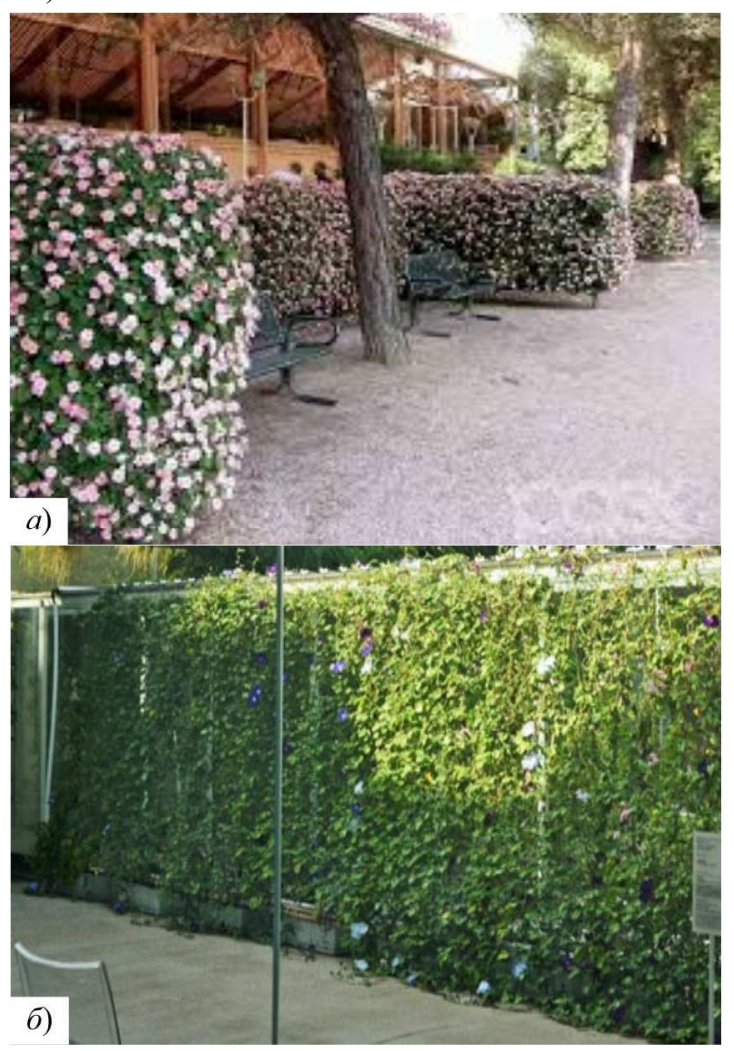

Рис. 4. Каркасні мобільні живоплоти

Окрім багатьох переваг мобільних живоплотів перед звичайними, в них $є$ і недоліки - висока ціна, потреба у постійному догляді, швидка втрата вологи, внаслідок підвищеної температури грунту у горшках. Частину 3 цих проблем вдається подолати завдяки новітнім розробкам, наприклад автономному поливу, а також застосуванню гідрогелю.

Під час транспортування та встановлення мобільної огорожі на об'єкті озеленення потрібно враховувати три основні чинники:

1) вага секції;

2) ширина, висота та довжина секції (ії габарити);

3) метод встановлення: звичайний, фіксувальний.

Звичайний метод встановлення - застосовують в експлуатації мобільних живих огорож, що не підлягати- 
муть сильному впливу вітру, можуть розташовуватися у внутрішніх дворах чи приміщеннях, або коли секція живої огорожі має достатню вагу і невелику парусність, що забезпечить стійкість кожного елементу конструкції. У разі звичайного встановлення мобільних живоплотів не використовують жодних додаткових засобів для фіксації до поверхні землі.

Фіксувальний метод передбачає закріплення, фіксацію секції до поверхні, на яку встановлюють живопліт, за допомогою додаткових елементів: мотузок, шурупів, дюбелів, анкерів тощо. За потреби можливо з'єднувати секції мобільного живоплоту між собою. Цей метод застосовують, як і антивандальний засіб, що убезпечить живопліт від руйнування, крадіжки.

Мобільні живоплоти класифікують за тривалістю використання: тимчасові- експлуатуються менш як три місяці. Сезонний - використання мобільної живої огорожі впродовж одного сезону від 3 до 9 місяців. Довгостроковий - використання мобільної живої огорожі понад 9 місяців. Також мобільний живопліт класифікують за можливістю переміщення: високомобільнийвага однієї секції живоплоту становить до 50 кг. $\mathrm{Ce}$ редньомобільний - вага однієї секції живоплоту - від 50 до 100 кг, це можливість переміщення однієї секції за допомогою 2-3 осіб чи міні-навантажувачем. Маломобільний - вага однієї секції живоплоту від 100 кг, його встановлюють за допомогою спецтехніки.

Для підвищення стійкості секцій живих огорож використовують також додаткові елементи, які збільшують вагу коробу.

Висновки. Мобільні живоплоти широко використовують у багатьох країнах світу. Достеменно, що вони є перспективний елемент для розвитку і збільшення озеленення населених місць України. Завдяки їм можна поліпшити комфорт та естетичну привабливість сильно урбанізованих місць у населених пунктах, наприклад центральні пішохідні вулиці, сквери, бульвари та площі міст. Мобільними живоплотами обмежують рух автотранспорту на певних відрізках дороги та можна швидко розмежувати простір.

Цей елемент озеленення також застосовують під час проведення ярмарок, концертів та інших заходів. Цей елемент озеленення цікавий як комерційний складник ландшафтного дизайну і він має всі характеристики для його розвитку та поширення.

\section{Перелік використах джерел}

Blanc, P. (2018). Vertical Garden. Konsept Focus Turkish, (pp. 114 117), August 2018. Retrieved from: https://www.verticalgardenpatrickblanc.com $/$ medias? $1 \mathrm{lg}=$ other\#

Dahlgaard, S. (2014). Mobile hedges. Haus der Kulturen der Wel Berlin. Campus. Retrieved from: https://www.anthropocene-curriculum.org/pages/root/campus-2014/slow-media/deconstructing-fences/mobile-hedges/

Myronchuk, K. V. (2016). Some Peculiarities of the Spatial Structure of Common Hedges and their Classification. Scientific Bulletin of UNFU, 26(5), 127-133. https://doi.org/10.15421/40260519

Simonova, D. (2018). Patrik Blank sadovyih del master. Sky Club Magazine Russia, 8, 162-165. Retrieved from: http://www.skyclub.ru/about/sky-cLub-magazine/?SHOWALL 1=1. [In Russian].

Timur, Ö.-B., \& Karaca, E. (2013). Vertical Gardens. Çankırı Karatekin University, Faculty of Forestry, Department of Landscape Architecture, Çankır1, Turkey, (pp. 587-622). https://doi.org/10.5772/55763

Vont mettre. (2018). Des tours vont mettre la forêt tropicale au coeur de la ville; la plus puissante éolienne du monde vise déjà le lage. Science \& Vie, 1210, (pp. 54-55). Mondadori France, Juillet 2018. Retrieved from: http://pvsamplersla5.immanens.com/fr/pvPageH5B.asp?puc $=003263 \& n u=1210 \& p a=4 \# 0$

Черновицкий национальный университет им. Юрия Федьковича, г. Черновцы, Украина

\section{КЛАССИФИКАЦИЯ МОБИЛЬНЫХ ЖИВЫХ ИЗГОРОДЕЙ}

Для временного или долгосрочного озеленения урбанизированных территорий, на которых нет возможности создания традиционных элементов озеленения, целесообразно создавать мобильные живые изгороди с применением новейших технологий. Моделирование процессов планирования, создания и формирования мобильных живых изгородей должно базироваться на сочетании декоративного, агротехнического и экологического принципов, а в дальнейшем - обеспечивать эколого-биологическую стабильность живых изгородей и их устойчивость к воздействию неблагоприятных природных и антропогенных факторов урбанизированной среды. Впервые предложена классификация мобильных живых изгородей, которая разделяет их на две группы - простые и каркасные. Мобильные живые изгороди классифицируют: по видовому составу - на чистые и смешанные; по высоте - низкие, средние и высокие. Также по продолжительности использования на одном объекте озеленения выделены: временные, сезонные, долгосрочные мобильные живые изгороди. В зависимости от размеров, веса одной секции, которая непосредственно влияет на мобильность данного элемента озеленения, а также по возможности перемещения, они подразделяются на: высокомобильные, среднемобильные и маломобильные. Приведены рекомендации по видовому составу, в используемых мобильных живых изгородях. Доказано, что мобильные живые изгороди являются перспективными для ландшафтного дизайна и озеленения территорий.

Ключевые слова: классификация; мобильная живая изгородь; секции; каркас для мобильной живой изгороди.

K. V. Myronchuk

Yuriy Fedkovych Chernivtsi National University, Chernivtsi, Ukraine

\section{CLASSIFICATION OF MOBILE HEDGES}

Today, among the prominent representatives of the new generation of greening and landscape design, we highlight mobile hedges. A mobile hedge is a hedge planted in containers (pots, boxes), separate sections of which, when sequentially arranged, form a dividing greening element, which serves as a traditional hedge. A significant advantage of mobile hedges is that they can be placed at sites where there is no need or it is impossible to create traditional elements of greening for a specified period of time. These are recreation areas, restaurants, cafes, summer playgrounds, exhibitions, fairs. By using mobile hedges, it is possible to restrict traffic on certain sections of the road. They will allow quick dividing the space and decorate the territory. Mobile hedges are classified according to their usage duration: temporary - they are used for less than three months; seasonal - the use of mobile living fences during one season from 3 to 9 months; long-term - the use of mobile living fence for more than 9 months. Mobile hedges are also classified by the possibility of moving: high-mobility hedge - the weight of one section of the hedge is up to 50kg; medium-mobility hedge - 
the weight of one section of the hedge is from 50 to $100 \mathrm{~kg}$, it is possible to move one section with 2-3 people or a mini loader; limited-mobility hedge - the weight of one section of the hedge is over $100 \mathrm{~kg}$, its installation is carried out with the help of special equipment. To improve the stability of living fence sections, it is possible to use additional elements that increase the weight of the box. Mobile hedges are divided into two groups - these are simple and carcass mobile hedges which are classified by species composition (in pure and mixed) and by height (low, medium and high). When creating carcass mobile fences, a support for plants is used - a framework that provides a varied shape and adorns the structural composition. When transporting and installing a mobile fence on a planting site, three main factors need to be taken into account: 1) weight of a section; 2) width, height and length of the section (its dimensions); 3) method of installation: simple, fixing. The simple installation method is used when operating mobile living fences that are not exposed to strong winds, can be located in the inner yard or on the premises, or when the section of the living fence has a sufficient weight and a small windage area, which will ensure the stability of each element of the structure. With the simple installation of mobile hedges, no additional means for fixing to the ground surface are used. The fixing method involves attachment - fixing the section to the surface on which the hedge is installed with the help of additional elements: rope, screws, dowels, anchors, and so on. If necessary, sections of the mobile hedge can be connected to one another.

Keywords: classification; mobile hedge; section; frame of mobile hedge. 